\title{
Tuberculosis in unvaccinated children, adolescents, and young adults: a city epidemic
}

\author{
J D HILL，D K STEVENSON
}

\begin{abstract}
In an epidemic of tuberculosis 41 new patients presented with the disease or were traced. The index patient was a part time barman in a public house. Four children in his family and four who lived in the same block of flats were infected. Only seven of the 41 patients had been vaccinated with BCG.

This epidemic indicates that the schools vaccination programme should be continued and the public made aware that tuberculosis still exists.
\end{abstract}

\section{Introduction}

With the reduction in the number of new notifications of tuberculosis there is a widespread belief that tuberculosis is no longer a health hazard. The media campaign against vaccination in general has led to a diminished compliance with BCG vaccination, and at least two district health authorities have discontinued their programme of BCG vaccination in schools. This has caused an increased susceptibility to infection in the young unvaccinated population.

For many years the incidence of tuberculosis in the white indigenous population of the United Kingdom has been declining, particularly in the young, and this has been the experience in Bradford. During 1982 notification of the disease in white adolescents and young adults increased considerably (table I). The epidemic emanated from a single index patient who was a regular customer and part time barman in a public house. Thirty four of the 41 infected patients had not had a BCG vaccination.
Chest Clinic, St Luke's Hospital, Bradford BD5 0NA

J D HILL, DM, MRCP, senior registrar

D K STEVENSON, FRCPE, consultant chest physician

Correspondence to: Dr D K Stevenson.
TABLE I-Notifications of tuberculosis in people aged under 30, 1976-82

\begin{tabular}{|c|c|c|c|c|c|c|}
\hline \multirow{3}{*}{ Year } & \multicolumn{4}{|c|}{ Age $15-29$} & \multirow{2}{*}{\multicolumn{2}{|c|}{ Children (age 0-14) }} \\
\hline & \multicolumn{2}{|c|}{ Male } & \multicolumn{2}{|c|}{ Female } & & \\
\hline & White & Asian & White & Asian & White & Asian \\
\hline $\begin{array}{l}1976 \\
1977 \\
1978 \\
1979 \\
1980 \\
1981 \\
1982\end{array}$ & $\begin{array}{r}6 \\
3 \\
5 \\
5 \\
5 \\
2 \\
18\end{array}$ & $\begin{array}{l}40 \\
29 \\
37 \\
30 \\
33 \\
22 \\
21\end{array}$ & $\begin{array}{r}7 \\
0 \\
2 \\
6 \\
6 \\
2 \\
17\end{array}$ & $\begin{array}{l}41 \\
35 \\
43 \\
50 \\
26 \\
28 \\
14\end{array}$ & $\begin{array}{l}2 \\
3 \\
3 \\
6 \\
1 \\
2 \\
3\end{array}$ & $\begin{array}{r}3 \\
9 \\
7 \\
7 \\
10 \\
4 \\
11\end{array}$ \\
\hline
\end{tabular}

\section{The outbreak}

The first patient was a 24 year old girl, who was admitted in February 1982 with left pleuritic pain and a cough and was found to have pulmonary tuberculosis with tubercle in the sputum. Forty five contacts, including 15 children, were examined. No case of disease was discovered, and the children all yielded negative results on Heaf testing. In the evenings she worked in a local public house. With the full cooperation of the landlord, customers and staff were checked and from this source the index patient was identified. $\mathrm{He}$ was a 31 year old unemployed labourer who spent a considerable amount of time in the public house, either as a customer or as a part time barman. He was generally uncooperative but after being persuaded to undergo mass radiography was found to have cavitating pulmonary tuberculosis with tubercle in the sputum. He was admitted to hospital in March.

Over nine months 41 cases of tuberculosis were discovered through this single source (table II); 38 patients were white, two were Ugandans, and one was a Kenyan Asian. The public house was in the city centre and was much frequented by the young. Most of the infections occurred during the Christmas holidays, when it was packed to capacity. Thirty two of the adult patients had been in the public house between December and March, when the source patient was thought to have been infective. Eight children and one adult with the disease either lived with the index patient or in the same block of flats.

Of the 41 patients, 27 who had been infected at the public house developed symptoms and reported initially to their general practitioners; four adults including the index patient and eight children were traced as contacts; and two cases were discovered on routine mass radiography. Over 300 regular customers at the public house were examined as contacts at mass radiography; no other case was 
TABLE II-Details of patients affected in outbreak

\begin{tabular}{|c|c|c|c|c|c|}
\hline $\begin{array}{l}\text { Case } \\
\text { No }\end{array}$ & $\begin{array}{c}\text { Age } \\
\text { (years) }\end{array}$ & Sex & $\begin{array}{c}\text { BCG } \\
\text { vaccination }\end{array}$ & $\begin{array}{c}\text { Traced } \\
\text { as } \\
\text { contact }\end{array}$ & Details of disease \\
\hline 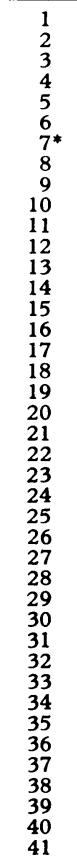 & $\begin{array}{r}24 \\
20 \\
19 \\
21 \\
24 \\
22 \\
31 \\
11 \\
17 \\
18 \\
21 \\
22 \\
35 \\
11 \\
4 \\
16 \\
33 \\
5 \\
3 \\
14 \\
8 \\
7 \\
18 \\
21 \\
17 \\
22 \\
19 \\
20 \\
24 \\
18 \\
33 \\
24 \\
25 \\
37 \\
18 \\
21 \\
17 \\
21 \\
17 \\
22 \\
21\end{array}$ & $\begin{array}{l}F \\
F \\
M \\
F \\
M \\
M \\
M \\
F \\
M \\
F \\
M \\
M \\
F \\
M \\
F \\
F \\
F \\
F \\
M \\
F \\
F \\
F \\
M \\
M \\
F \\
M \\
M \\
M \\
F \\
M \\
M \\
M \\
M \\
M \\
F \\
M \\
F \\
M \\
M \\
M \\
M\end{array}$ & $\begin{array}{l}\text { No } \\
\text { No } \\
\text { No } \\
\text { No } \\
\text { No } \\
\text { No } \\
\text { No } \\
\text { No } \\
\text { No } \\
\text { No } \\
\text { No } \\
\text { Yes } \\
\text { No } \\
\text { No } \\
\text { No } \\
\text { No } \\
\text { No } \\
\text { No } \\
\text { No } \\
\text { No } \\
\text { No } \\
\text { No } \\
\text { Yes } \\
\text { No } \\
\text { Yes } \\
\text { No } \\
\text { No } \\
\text { No } \\
\text { No } \\
\text { Yes } \\
\text { No } \\
\text { No } \\
\text { Yes } \\
\text { No } \\
\text { No } \\
\text { Yes } \\
\text { Yes } \\
\text { No } \\
\text { No } \\
\text { No } \\
\text { No }\end{array}$ & $\begin{array}{l}\text { No } \\
\text { No } \\
\text { No } \\
\text { No } \\
\text { Yes } \\
\text { No } \\
\text { Yes } \\
\text { Yes } \\
\text { No } \\
\text { No } \\
\text { No } \\
\text { No } \\
\text { No } \\
\text { Yes } \\
\text { No } \\
\text { No } \\
\text { No } \\
\text { Yes } \\
\text { Yes } \\
\text { Yes } \\
\text { Yes } \\
\text { Yes } \\
\text { No } \\
\text { No } \\
\text { No } \\
\text { No } \\
\text { No } \\
\text { Yes } \\
\text { No } \\
\text { No } \\
\text { No } \\
\text { No } \\
\text { No } \\
\text { No } \\
\text { No } \\
\text { No } \\
\text { No } \\
\text { Yes } \\
\text { No } \\
\text { No } \\
\text { No }\end{array}$ & $\begin{array}{l}\text { Pulmonary disease; sputum positive } \\
\text { Pulmonary disease; sputum positive } \\
\text { Pulmonary disease; sputum positive } \\
\text { Pleural effusion } \\
\text { Early upper zone disease } \\
\text { Early upper zone disease } \\
\text { Pulmonary disease; sputum positive } \\
\text { Primary infection } \\
\text { Pleural effusion } \\
\text { Early upper zone disease } \\
\text { Pleural effusion; biopsy positive } \\
\text { Pleural effusion; biopsy positive } \\
\text { Pleural effusion } \\
\text { Primary infection } \\
\text { Primary infection } \\
\text { Pleural effusion } \\
\text { Pleural effusion } \\
\text { Prophylactic chemotherapy } \\
\text { Prophylactic chemotherapy } \\
\text { Prophylactic chemotherapy } \\
\text { Prophylactic chemotherapy } \\
\text { Prophylactic chemotherapy } \\
\text { Pleural effusion; biopsy positive } \\
\text { Pleural effusion } \\
\text { Pleural effusion; biopsy positive } \\
\text { Pleural effusion; culture positive } \\
\text { Pleural effusion } \\
\text { Prophylactic chemotherapy } \\
\text { Pleural effusion } \\
\text { Pleural effusion } \\
\text { Pleural effusion; culture positive } \\
\text { Pleural effusion } \\
\text { Pleural effusion } \\
\text { Lung and liver biopsy positive } \\
\text { Early upper zone disease } \\
\text { Pleural effusion; culture positive } \\
\text { Pleural effusion; biopsy positive } \\
\text { Pleural effusion } \\
\text { Pulmonary disease; sputum positive } \\
\text { Pulmonary disease; sputum positive } \\
\text { Tuberculous meningitis }\end{array}$ \\
\hline
\end{tabular}

*Index case.

discovered. Twenty six patients were admitted to hospital, eight with pulmonary tuberculosis, 16 with pleural effusions, one child with a primary infection, and one man with tuberculous meningitis. The remainder were treated as outpatients. Five children and one adult were given chemoprophylaxis.

Two of the early patients had pulmonary tuberculosis that yielded a positive result on smear testing and had been in previous contact with the index case. Both were careful in personal hygiene, protecting the environment against explosive coughing and in sputum disposal In one case 63 family and friends including 14 children were examined, and in the other 33 close contacts including nine children. No case of tuberculosis was discovered, and all 23 children yielded negative results on Heaf testing. Both patients had most probably been infected by the index patient. Contact tracing in the index case yielded four infected children in the patient's family and a further four children and one adult who lived in the same block of flats as him.

All the patients in the series yielded strongly positive results on Heaf testing (grades 3 and 4). Eleven patients had pulmonary tuberculosis: seven yielded positive results on smear testing and four had upper zone infiltrations. Twenty patients presented with pleural effusions, of whom 16 were admitted to hospital. All required repeated aspirations. The effusions were all lymphocytic exudates; bacteriological or histological confirmation was obtained in eight. In patients with primary infections the disease was diagnosed radiologically by the finding of enlarged paratracheal or hilar glands for which no other cause was apparent.

The patients given chemoprophylaxis were primarily unvaccinated children with grade 4 reactions on Heaf testing and normal chest radiographs.

Treatment, with patients notified according to the new procedures of notification, ${ }^{1}$ was with antituberculous chemotherapy given for nine months and supervised by chest physicians ${ }^{2}$; it was changed only in the event of drug reactions. ${ }^{3}$ Patients whose sputum contained tubercle were treated initially with rifampicin, isoniazid, and pyrazinamide and the remainder with rifampicin, isoniazid, and ethambutol in appropriate doses. Pyrazinamide and ethambutol were stopped after two months. Pyridoxine was given according to acetylator status, and steroids were given initially for large and persisting effusions and in three patients with drug toxicity. Chemoprophylaxis comprised ethambutol and isoniazid for six months. All patients subsequently became well, and there were no serious drug induced side effects.
The reasons for not having received BCG were many and diverse: several were "too young"; in some cases parental consent had been withheld; and in others absence from school, eczema, and "didn't like needles" were common excuses. In the routine tuberculin testing and BCG vaccination of school children in the Bradford district 1977-82, which includes the indigenous and immigrant population, the average available number of school children between 10 and 11 years was 5500 . The yearly average number skin tested was $4919(89 \%)$, the average number found to be positive was 799 $(15 \%)$, and the average number vaccinated was $3809(69 \%)$. Thus most school children in Bradford are protected by BCG vaccination. Seven adolescents who had received BCG vaccination and had good scars presented with pleural effusions; in five bacteriological or histological confirmation of the diagnosis was obtained. The presence of the disease in these seven is hard to explain, but probably they succumbed to reinfection.

With such an apparently virulent strain of organism arrangements were made for typing at the Cardiff Reference Laboratory. The strain was not found to have any unusual cultural characteristics, however, and was fully sensitive to all antituberculous drugs in all cases in which positive cultures were obtained.

Three months after the onset of symptoms in the first few cases an article about the epidemic appeared in a local paper and was quickly followed by a local radio broadcast. As a result about 300 people, regular customers of the public house, submitted themselves for mass miniature $x$ ray examination. The public house immediately became deserted, and the landlord sustained an estimated loss of $£ 13000$ in custom over the next two or three months. His business subsequently recovered. In fact, once the source of infection had been removed and treated with chemotherapy the danger of infection was eliminated.

This epidemic affected almost exclusively non-vaccinated adolescents and young adults. It resulted from a single source patient who excreted tubercle bacilli by unprotected explosive coughing into a crowded community of young people. The susceptible in this environment developed tuberculous infections and disease, but over 300 regular customers did not develop disease and possibly they were protected by prior BCG vaccination.

\section{Discussion}

We have reported an epidemic of tuberculosis in a city with an established record for preventing and treating the disease. Bradford has an active programme tailored to the Asian community, which includes BCG vaccination of all Asian children born in or coming to live in the city. The Asian population with its high incidence of the disease is protected to a high degree by BCG, by routine radiological supervision, and by prophylactic chemotherapy when necessary. All children, white and Asian, undergo Heaf testing and are given BCG vaccination when necessary at the age of 10 or 11 . Despite the difference in policy between the white and Asian communities the number of cases of tuberculosis in the white indigenous population is no greater than the UK average. There has been no epidemiological evidence of cross infection between populations.

In 1980 the British Thoracic Association ${ }^{3}$ estimated that vaccination of 100000 British school children would prevent only 44 cases of tuberculosis in the ensuing 15 years. It has been suggested that it may soon be more cost effective to stop the mass vaccination programme and treat the few extra cases with chemotherapy. Several other epidemics of tuberculosis have occurred in different areas over the past few years, ${ }^{4-6}$ although the number of non-vaccinated patients affected is not clear in each case. Abandoning vaccination programmes in favour of treating the extra cases might therefore prove less cost effective than was originally thought.

Spencer-Jones stated recently that tracing casual contacts produces few cases of disease, ${ }^{5}$ and this was certainly our experience. As described in that paper, most of our patients developed symptoms and were referred by their general practitioners. The disease was not found among any of the 300 who submitted themselves for mass $x$ ray examination as casual contacts, despite the time lag after the presentation of the source case. The persistence of our health visitor in tracing 
contacts, however, yielded 12 patients with the disease, of whom eight were children, which underlines the efficiency of the service if properly applied.

The public reaction to the articles in local papers was interesting, and evidently there are still many misconceptions about tuberculosis. Most of the people who submitted themselves for $x$ ray examination were totally ignorant of the implications of the disease and reacted in a way more reminiscent of the plague or smallpox. This shows again how powerful an influence the media may be in medical matters. The unjustified loss of trade to the public house must also be a matter of some concern and reflects to some extent the public attitude to the disease.

In conclusion, this epidemic serves to emphasise two long established but probably forgotten truths about tuberculosis. Firstly, tuberculosis still exists in this country and is not merely a disease of immigrants, social outcasts, and alcoholics; in non-vaccinated people it remains a highly contagious disease of young adulthood. The BCG vaccination, however, is safe, free from systemic side effects, and of proved efficacy when given at the age of maximum susceptibility to the disease. Every effort should be made to pursue the schools vaccination programme, particularly in children who initially default. Secondly, the public should be made aware that tuberculosis in all forms can be cured completely with drugs at little personal inconvenience.

We thank the Bradford chest physicians for access to their patients.

\section{References}

1 Joint Tuberculosis Committee of the British Thoracic Association. Notification of tuberculosis: a code of practice for England and Wales. Br Med F 1982;284:1454-6.

2 Wardman AG, Williams SE, Curzon PGD, Page RL, Cooke NJ. Tuberculosis: who should prescribe? $\mathrm{Br}$ Med $\mathcal{F} 1982 ; 284: 569-73$.

${ }^{3}$ Research Committee of the British Thoracic Association. Report. Effectiveness of BCG vaccination in Great Britain in 1978. $\mathrm{Br} \mathcal{F}$ Dis Chest $1980 ; 74: 215-27$.

${ }^{4}$ Smith WHR, Davies D, Mason KD, Onions JP. Intraoral and pulmonary tuberculosis following dental treatment. Lancet 1982;i:842-4.

${ }^{5}$ Spencer-Jones J. A tuberculosis outbreak in Deal, Kent. Lancet 1982; i : 1060-1.

${ }^{6}$ Communicable Disease Surveillance Centre. Communicable disease report 1979 , No $9 ; 1979$, No $22 ; 1980$, No $23 ; 1980$, No $50 ; 1981$, No $36 ; 1982$, No 11 .

(Accepted 9 March 1983)

\title{
Clinical range of neonatal rotavirus gastroenteritis
}

\author{
J DEARLOVE, P LATHAM, B DEARLOVE, K PEARL, A THOMSON, I G LEWIS
}

\begin{abstract}
A baby admitted to a special care baby unit with profuse watery diarrhoea was found to have a rotavirus infection. A total of 196 babies were admitted to the unit over the next year. Routine stool samples were taken weekly from all babies and additional samples were taken from all babies who developed clinical signs suggesting sepsis. A total of 76 babies excreted rotavirus; 32 of these developed a diarrhoeal illness, 12 of whom were severely ill with bloody diarrhoea and abdominal distension; and two had perforations. The smaller, sicker babies who stayed in hospital longer were more likely to acquire infection; colostrum did not confer protection against rotavirus or symptomatic infection. The outbreak of rotavirus declined independently of the measures taken to eradicate it.
\end{abstract}

Our findings suggest that neonatal rotavirus infection may occasionally cause severe gastrointestinal problems.

Ormskirk and District General Hospital, Ormskirk L39 2AZ

J DEARLOVE, FRCP(C), MRCP, consultant paediatrician

B DEARLOVE, MSC, research worker

Department of Paediatrics, Charing Cross Hospital, London W6 8RF P LATHAM, MRCP, senior registrar

South Hammersmith District Health Authority, London W6

K PEARL, MRCP, senior clinical medical officer, South Hammersmith District

Department of Paediatrics, Hammersmith Hospital, London W12 A THOMSON, MRCP, research registrar

Department of Paediatrics, Queen Victoria Hospital, Adelaide, S Australia

I G LEWIS, MB, MRCP, lecturer in neonatology

Correspondence to: Dr J Dearlove.

\section{Introduction}

In December 1980 an infant was admitted to the special care baby unit at Charing Cross Hospital. He developed a profuse watery diarrhoea. Rotavirus was isolated from his stools and also from his mother's faeces. Over the next year we treated a large number of infected babies with a very high morbidity. Although neonatal rotavirus infections are generally regarded as relatively benign, ${ }^{1}$ our experience was very different. ${ }^{2}$

\section{Materials and methods}

All babies admitted to the special care baby unit in the year after the index case-that is, from 18 December 1980 to 18 December 1981were studied. Cases arising after 18 December 1981 were excluded from the study. All the babies studied were seen by at least two of the authors. Later in the study period, we attempted a similar surveillance of asymptomatic babies in the postnatal wards, but those results are not included here.

An initial stool sample was taken from all babies; thereafter stool samples were taken weekly and cultured for bacterial pathogens. Stools were also examined for the presence of rotavirus. In addition, any baby who appeared ill and was being investigated for a septic condition had a stool sample examined for the presence of rotavirus. Initially, the stool specimens were examined by electron microscopy. After three months, this technique was replaced by semiquantitative enzyme linked immunoassay (Rotazyme), which is of comparable sensitivity ${ }^{3}$ as we found when using both techniques at the beginning of our study. The Rotazyme test may give negative results or be graded optically as positive from one (weakly positive) to six (very strongly positive). We regarded a result of grade two, as indicative of rotavirus infection. The date that the first stool with positive results was taken from the patient was assumed to be the date that the baby acquired rotavirus. The date in the baby's notes indicating a clear change in clinical state as defined by our criteria was taken to be the date that the baby became ill.

The babies who excreted rotavirus appeared to have a wide range of gastrointestinal symptoms varying in severity from those resembling necretising enterocolitis to mild diarrhoea. The babies were classified 